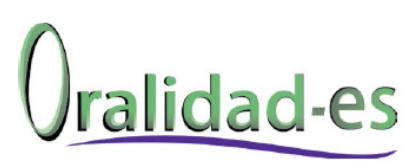

REVISTA DE LA RED IBEROAMERICANA DE ESTUDIOS

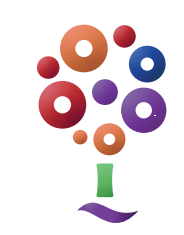

\title{
Tres momentos de la oralidad. Una mirada sobre lo escuchado y lo escrito
}

\author{
Gloria Mariela Rojas-Álvarez \\ glorjamar@gmail.com \\ Universidad Distrital Francisco José de Caldas, \\ Colombia
}

Rojas-Álvarez, G. M. (2020). Tres momentos de la oralidad. Una mirada sobre lo escuchado y lo escrito. Oralidad-es, 6, 1-15. https://revistaoralidad-es.com/index.php/ro-es/article/view/129/129

Fecha de recepción: 04 de noviembre de 2020 / Fecha de aceptación: 22 de diciembre de 2020

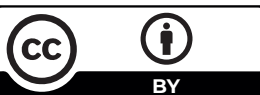




\section{Resumen}

Este artículo de corte ensayístico presenta algunas reflexiones consideradas desde tres momentos y entornos determinantes de la oralidad. En primer lugar se hace referencia a lo netamente oral. En seguida se menciona un entorno de oralidad secundaria, condicionada por la escritura. En el tercero la oralidad y la escritura se emulsionan con formas propias de la era electrónica, en la que lo audiovisual y lo virtual marcan nuevos rumbos de comprensión e interacción. Esta mirada sobre las variaciones y transformaciones de la oralidad, en esos tres momentos referidos, evidencian que la lectura y la escucha, como procesos de recepción, quedan, generalmente, subsumidos a los procesos de producción: escritura y habla. Por ello, se invita al silencio como camino de la escucha (de sí, los otros y lo otro), que permite que cualquier réplica necesaria y subsiguiente tenga mayor impacto y profundidad.

\section{Palabras Clave}

Escritura; escucha; oralidad primaria; oralidad secundaria; oralidad terciaria

\section{Abstract}

This essay presents some reflections considered from three moments and determining environments around orality. A primary environment referring to the purely oral, followed by an environment of secondary orality conditioned by writing, and in a third moment, with an environment in which orality and writing are emulated with the forms typical of the electronic age in which the audiovisual and the virtual mark new directions of understanding and interaction. This glance on the variations and transformations around orality in these three moments shows that reading and listening as reception processes are generally subsumed in the production processes: writing and speaking. For this reason, silence is invited as the path of listening (to oneself, to others and to the other), which allows any necessary and subsequent response to have greater impact and depth.

Keywords

Listening; Primary Orality; Secondary Orality;

Tertiary Orality; Writing 


\section{Introducción}

La palabra ha estado atravesada por multiformes variaciones, desde que la humanidad tiene conciencia del escuchar y el hablar. Como consecuencia, en su transcurrir ha estado aliada con el cuerpo, el rostro, los gestos, los sonidos, las voces y los silencios. Desde ese conglomerado en el que lo audible y lo inaudible fundan una existencia simbiótica entre el escuchar y el hablar emerge la oralidad, pues:

[...] no sólo es voz, expresión oral o habla, es el equilibrio justo entre el silencio de la escuch y y la palabra que se pronuncia, ya que ambos son indisociables. Siendo [...] la oralidad escuch a y silencio, vemos que es en tiempos relativamente recientes, que se empieza a dar cierto auge a su indagación, concibiendo el habla y la escucha como procesos inherentes (Rojas, 2019, p. 61).

Si asumimos esta confluencia entre el hablar y el escuchar entendemos que esta última no representa un papel pasivo ni silencioso, sino que, por el contrario, es muy activo (Lenkersdorf, 2008; Gutiérrez-Ríos y Uribe-Hincapié, 2015; Rojas, 2019), pues sin la escucha el habla no tiene sentido, no puede seguirse, no despierta interés y no puede comprenderse. Entonces, se evidencia su concatenación indisociable, porque se validan y se alimentan mutuamente (Cassany, Luna y Sanz, 1994).

Sin embargo, la relevancia que ha tenido el habla, la palabra dicha, la retórica y la oratoria como procesos de producción se ha extendido, generalmente, por encima del proceso de recepción implicado en el escuchar. Asimismo, el sentido de la oralidad no puede dejar de lado el papel secundario que ha tenido frente a la escritura, que desde su aparición ha subsumido a aquella (Ong, 1987; 2017). Esto cobra un acento muy marcado en la escuela y en el ámbito pedagógico, en los cuales las prácticas y la investigación se enfocan en el proceso escrito más que en el oral (Rojas, 2019).
Estas reflexiones permiten el acercamiento a tres momentos claves de la oralidad, los cuales son el foco principal de este artículo. El primero se refiere a la oralidad ágrafa (oralidad primaria), aquella en la que no hay rastros de escritura y hay correspondencia pura solo con lo oral-auditivo. El segundo tiene que ver con la oralidad secundaria, aquella que está unida a lo escrito. Finalmente, el tercer momento es aquel en $\mathrm{n}$ el que la oralidad se explaya en estos tiempos informáticos y electrónicos, por medio de formas emulsionadas de hablar, escuchar, leer, escribir y representar. Estas prácticas están permeadas e impactadas por todo tipo de medios tecnológicos que han transformado nuestras subjetividades, así como nuestras formas de comunicarnos y relacionarnos. En estas subjetividades se hace necesario el llamado hacia el silencio como condición ineludible para escuchar y escucharnos.

\section{La escucha desde la oralidad primaria}

La oralidad primaria es percibida como aquella en la que predomina la voz y la escucha, sobre todo en sociedades originarias ágrafas, en las que la cultura representa unas maneras de hablar, así como de escuchar la voz, desde una conciencia y percepción del mundo específicas (Ong, 1987; Abascal-Vicente, 2002). El habla y el sonido unidos al cuerpo tienen muchísima importancia, permitiendo que la palabra limpia de escritura haga que la viva voz o la palabra oral sean puntual, pensada y no se use vana e innecesariamente, porque vale por sí misma. Por consiguiente, es pronunciada con intenciones específicas, que implican cuidado y precaución, ya que está de por medio el compromiso de la credibilidad que ella emite en sí. De allí que el valor del silencio y la escucha sean, también, bastante valorados, tal como lo percibe Kent Nerburn (1994) en sus conversaciones con un anciano indio de la tribu lakota en Norteamérica: "People should think of their words like seeds. They should plant them, then let them grow in silence" (p. 68). 
Para las culturas orales que no han tenido conocimiento de la escritura, la palabra además de tener un fuerte fundamento mnemotécnico del pensamiento, tiene un gran poder y se transforma en hecho, en acontecimiento y en realidad, aunque no haya huella visual en lo que se escucha, ya que el sonido solo existe mientras deja de ser (Ong, 1987). A lo que se añade que, cuando no se ha dependido de la escritura, la transmisión oral del conocimiento y de la experiencia hacia las generaciones más jóvenes ha sido, en gran medida, asignada a los adultos mayores como los dadores de la palabra (oral), la cual contiene poder porque es escuchada y asumida. Por esto, en muchas culturas solo se puede ser autoridad elegida si se sabe, también, escuchar (Abascal-Vicente, 2002; Nerburn, 1994; Lenkersdorf, 2008).

Pero con el arribo de la escritura, la palabra despojada de la voz se hace prisionera en superficies sólidas (de metal, piedra, bambú, cuero o papel) y su valor establece derechos, responsabilidades y compromisos, como lo reconoce Niño (2014, p. 57):

El chamán, que es el custodio individual del sueño colectivo ordenado en el mito, es sustituido por el notario. De una función de servicio a la comunidad se pasa a un funcionario que saca usufructo a las necesidades que tiene la comunidad de registrar la memoria de sus haberes. El apretón de manos o el abrazo que sellan un acuerdo oral es sustituido por una firma o una huella digital. [...] Las palabras ya no quedan a merced del viento ni de la versión de quien las escucha.

Cuando surge la escritura hay una ruptura frente a la conciencia oral ágrafa. Los registros visuales de la escritura se vuelven instrumentos para remplazar el sonido de la palabra oral, cobrando mayor valor que esta, porque su soberanía queda evidenciada en objetos físicos, que dejan marcas y rastros estáticos que se agudizan ante la invasiva cultura visual que ha tendido a hacernos suponer que la sola visión da acceso satisfactorio a lo real o que el elevamiento de lo visual debería significar la supresión de todos los otros sentidos. Así, la palabra escuchada queda subsumida en un segundo plano (Ong, 2017).

Los sonidos orales, que desaparecen cuando son escuchados, dejan como única posibilidad de certidumbre el permanecer en la memoria de los seres humanos, quienes le adjudicaron un valor inconmensurable por milenios. Con la aparición de la escritura, la oralidad como tal queda relegada a un segundo plano, y hoy, definitivamente, ha quedado a expensas de objetos y dispositivos que muchas veces desplazan al otro que habla o que escucha.

\section{La oralidad secundaria desde la escucha y la lectura}

Los confines clásicos nos han señalado que en la escritura griega y latina no había separación de palabras entre sí, por lo que no era fácil el ejercicio de la lectura. Es así como se recomendaba escribir después de haber leído y lo que se escribía era necesario volverlo a leer y a releer en voz alta, incluso cuando la lectura no era sino para uno mismo. La lectura no se hacía sólo con la vista y el lector de la antigüedad clásica era el encargado de distinguir las palabras y la puntuación (Foucault, 2002; Ong, 2017).

En relación con ello, para Ferreiro (2001) por medio de esa página de la antigüedad clásica sin puntuación y sin diferenciación de palabras se probaba al lector como intérprete, ya que el "texto clásico estaba hecho para que 'sonara', al igual que una partitura musical. Y, también al igual que la música, lo de menos eran las letras [...] Lo que realmente importaba era la interpretación" (p. 45).

En uno de los periodos posteriores de transición entre el declive de la oralidad y el terreno cada vez más ganado de la escritura, se percibe que: 
[...] en algún momento de la historia la

palabra escrita le ha quitado al habla su autoridad, eso se desarrolló como parte de un movimiento gradual. En determinado momento del pasaje de las sociedades medievales de su estadio oral a su estadio letrado se produjo una emulsión particular entre oralidad y escritura. En ese pasaje finalmente, en algún momento, la escritura logró imponerse como la figura del progreso. Pero mucho antes de que esto sucediera existió la sociedad medieval sumergida en una oralidad libre y popular. Contra esa oralidad libre se había impuesto la autoridad represiva del clero y la escritura. (Mendoza, 2019a, p. 6).

Así, desde estas épocas medievales, en las que se está tratando de consolidar la escritura y la lectura, se empieza a percibir la gran revolución frente al comportamiento lector ${ }^{1}$, que, contrario a lo que mucho se predica, fue anterior a la imprenta como invención tecnológica, según Emilia Ferreiro $(2001)^{2}$. Esta autora recuerda que la transición de la lectura en voz alta (usual en épocas medievales), a la lectura en silencio y en soledad tardó varios siglos en recibir aceptación, porque fue una ruptura que atentó contra lo establecido hasta el momento y marcó un antes y un después, ya que los copistas de la cultura medieval originaron la división de palabras como unidades gráficas que permitían la comprensión inmediata, prescindiendo de la voz de un intérprete-lector.

\footnotetext{
${ }^{1}$ Se tiene de antemano presente que la figura del 'lector' era propia de una clase muy particular de la sociedad y con fines muy precisos.

${ }^{2}$ Es necesario aclarar que, por lo vasto del tema, en este segundo momento no se tratará la bifurcación que surge entre el antes y el después de la escritura con la aparición de la imprenta. Tema que amerita otro artículo.

${ }^{3}$ Esta escena es aclarada por Ong (2017, p. 58): "In his Confessions [...], Augustine makes special note of the fact that when he once dropped in on Ambrose, Bishop of Milan, he found Ambrose reading to himself without making any sound. Augustine's note shows that silent private reading was not entirely unknown, but it also shows that it was certainly singular and deserving of comment".
}

Así, fue inevitable que se llegara a la página revolucionaria que llevó a la lectura individual, como indica Ferreiro (2001). Esta modalidad permitía que la gramática fuera más legible, posibilitando la citación de fragmentos y visibilizando, desde el comienzo, el título y el autor. Adicionalmente, se admitió la numeración de las páginas, que se tuviera un índice, una división de capítulos y puntuación, entre muchos otros cambios revolucionarios. Esta lectura individual, fue, también, el inicio de una lectura no censurada socialmente:

La nueva intimidad con el texto genera dos movimientos complementarios en un mismo acto de complicidad: la libertad del lector, cuya interpretación queda momentáneamente fuera de la esfera de la censura, y la libertad del escritor, dueño de su pluma y su voz apagada, que puede permitirse expresar, en la intimidad de la celda o de la recámara, lo que ninguna voz podría expresar en voz alta (Ferreiro, 2001, p. 48).

Haciendo alusión a San Agustín en sus Confesiones, Borges (1999) menciona que era inquietante este singular espectáculo: "un hombre en una habitación, con un libro, leyendo sin articular las palabras" (p. 104), pues se omitía el signo sonoro tan propio de la mencionada lectura en voz alta, para pasar al signo de la escritura que permitía disfrutar en silencio lo leído 3 .

Esta lectura silenciosa, tan naturalizada y común en nuestros días, no lo era hace varios siglos, y es esa relación con el silencio lo que marca la asociación con la escucha, ya que es un otro el que se tiene al frente. Es decir, no se cuenta con su presencia física, pero sí el registro escrito de su voz, lo que lleva a que se pueda asimilar la lectura y la escucha como procesos receptivos que entrañan similitudes. Por ello, Gadamer (1998) dice que comprender textos es "entenderse en una especie de conversación” (p. 130) y que "escuchamos la voz apagada de la letra escrita" (p. 181), porque el "oír y el leer poseen la misma estructura temporal que el comprender” (p. 345). 
En esa misma línea, Cassany, Luna y Sanz (1994, p. 89) van a plantear que "escuchar y leer son habilidades activas en tanto que el individuo tiene que realizar muchas operaciones que, aunque no sean observables externamente, son complejas y laboriosas", ya que, siendo procesos de recepción, van al interior y es difícil evidenciar lo que sucede. Es decir, se necesita estar en o hacerse silencio para leer y para escuchar.

Por otro lado, la valoración de Ong (1987) se dirige a la oralidad que, aunque se detiene mínimamente en el sonido, no profundiza en la escucha, dirigiéndose a la escritura, más que a la lectura. Es decir, la palabra en su ambiente oral natural forma parte de un presente existencial real: la articulación hablada es dirigida por una persona real a otra persona real o a otras personas reales, dentro de marcos reales, que siempre incluyen más que las meras palabras y modifican situaciones totales, más que verbales: "una palabra debe producirse con una $\mathrm{u}$ otra entonación o tono de voz: enérgica, excitada, sosegada, irritada, resignada" (Ong, 1987, p. 102), lo que da el aliento de la voz. Esto, desde la oralidad primaria, crea un tipo de conciencia y proceder frente al mundo.

Pero en la escritura las palabras están solas, ya que, al componer un texto, quien produce el enunciado escrito también está solo y ahí ya no hay entonación alguna. "En un texto, la entonación puede señalar el tono en un grado mínimo: un signo de interrogación o una coma, por ejemplo, generalmente requieren que la

\footnotetext{
${ }^{4}$ Esta escena también es retomada por Ong (1987) y por Sontag (1997).

${ }^{5}$ Esto también es retomado por Ong (2017, p. 55): “[...] the philosopher Socrates left none of his philosophy in writing. Despite the fact that Plato' philosophy, as we have seen, was the product of literacy, Plato was deeply and explicitly committed to the spoken word. He wrote down some of Socrate's teaching in a tight, pointed style far removed from oral modes, but he calculatingly used the dialogue form to give the teachings something like their original oral cast, protesting un his Seventh Letter that one cannot put what is really essential to wisdom in writing, for this is to falsify it".
}

voz se eleve un poco" (Ong, 1987, p. 103). Esta diferencia entre la oralidad y la escritura ha llevado a que se haya caído en comparaciones de una en detrimento de la otra. Por ello, la clásica dicotomía que recuerda el "lamento platónico" (Tolchinsky, 2001), añorando la oralidad sobre la escritura porque aquella contempla la potencia del conocimiento desde la memoria, sin artefactos, sin artilugios y sin representaciones ficticias que puedan remplazar la vitalidad de la voz por simulacros, artificios que engañan la mente y la conciencia desde lo escrito.

Así, los discursos escritos al leerlos no piensan, ya que no pueden dar explicación y van a responder siempre lo mismo, rodando de mano en mano, sin saber con quién se debe hablar y con quién se debe callar. Según Platón (1995), autor que retoma la fábula egipcia de Thamus y Theuth, la escritura produce olvido al descuidar la memoria. Además, fiarse de lo escrito es recordar desde afuera, desde lo ajeno, no desde y por sí mismo 4 .

En la Carta VII, Platón (2007) expresa que la escritura deja vulnerable a quien recurra a ella, ya que una persona sensata se debe guardar de confiar "por escrito cuestiones serias, exponiéndolas a la malevolencia y a la ignorancia de la gente [permaneciendo estas] en la parte más preciosa de su ser" (p. 378). Pero el desprecio del filósofo a la escritura trasciende en Fedro porque esta opaca la memoria:

[...] no producirá sino el olvido en las almas de los que la conozcan, haciéndoles despreciar la memoria; fiados en este auxilio extraño abandonarán a caracteres materiales el cuidado de conservar los recuerdos, cuyo rastro habrá perdido su espíritu [porque la escritura no es] un medio de cultivar la memoria, sino de despertar reminiscencias (Platón, 1995, p. 341). ${ }^{5}$ 
También cuando Platón (1995) dice que la escritura da a los discípulos "la sombra de la ciencia y no la ciencia misma" (p. 341) nos remite a otro contexto y otra época, recordando a de Saussure, quien, a principios del siglo XX, trata de guardar una coherencia radical con su perspectiva alrededor de la lingüística, sustentándola netamente desde la oralidad en sí misma. Para este lingüista suizo, la palabra escrita usurpa el papel principal de la palabra hablada de la cual es solo imagen y "se llega a dar a la representación del signo vocal tanta y más importancia que al signo mismo. Es como si se creyese que para conocer a alguien vale más mirar su fotografía que su rostro" (de Saussure, 1998, p. 53). ${ }^{6}$

Sin ser tan radical, y desde otras fronteras, Zambrano (2002) también da prevalencia a la voz y a lo que se escucha porque esto permite aprender de inmediato, en cambio con la escritura:

\section{[...] hay que restituir acento y voz para que así sintamos que nos está dirigida. Con la pa- labra escrita tenemos que ir a encontrarnos a la mitad del camino. Y siempre conservará la objetividad y la fijeza inanimada de lo que fue dicho. (p. 16)}

Por eso es inevitable que emerja la relación que tienen la lectura y la escucha como procesos de recepción, que generan comprensión, entendimiento e interpretación (Cassany, Luna y Sanz, 1994). Si leer es como escuchar la voz de alguien (Gadamer, 1998), apropiarse de un texto es como escuchar lo que el texto dice, algo que se abre e inquieta, y esa relación es "una forma de atención, una actitud de escucha, una inquietud, una apertura” (p.28).

Frente a este panorama, en líneas generales, vemos que para el caso de los procesos de producción (expresión oral y escritura) hay más oposición, divergencia y dicotomía (Ong, 1987); pero en el caso de los procesos de recepción (lectura y escucha) se percibe más tendencia a lo relacional, la semejanza y la unidad. Más allá de esto, y de la clásica dicotomía mencionada en esta oralidad secundaria como la llama Ong (1987), hoy es inevitable no incorporar otras formas de oralidad, que hacen eco en un tercer nivel o entorno y que tienen que ver con las formas de comunicación actuales, que no solo cambian la manera en que se habla y se escucha, sino, también, las subjetividades en sí mismas (Abascal-Vicente, 2002; Vázquez, 2014; Contreras, 2015; Sibilia, 2015). ${ }^{7}$

\section{El tercer entorno de la voz, la escritura y la escucha: oralidad terciaria}

En la actualidad la cultura escrita y la oralidad están atravesadas por tecnologías mediadas por la virtualidad que, como recursos externos, no dejan de transformar nuestras subjetividades, nuestras formas de percibir el mundo, expresarlo y representarlo, porque han afectado la palabra y han modificado nuestras relaciones

\footnotetext{
${ }^{6}$ Tanta búsqueda de consistencia en Saussure con respecto a la oralidad llevó a que su famoso libro Curso de lingǘstica general no fuera escrito directamente por él, sino que fuese la recopilación de las notas y manuscritos que lograron hacer sus estudiantes, Charles Bally y Albert Sechehaye, porque Saussure destruía sus borradores y cualquier escrito provisional que preparaba para sus clases (de Saussure, 1998).

${ }^{7}$ Es necesario no pasar desapercibido el requerimiento frecuente que, desde su consolidación, ha hecho la escuela de la lectura y la escritura, siendo, sin embargo, muy paradójica la poca valoración que se le ha dado a la oralidad (y en esta, a la escucha) en los confines escolares. Todo lo que se habla en la escuela está atravesado por esa oralidad secundaria que no puede escapar a los procesos de lectura y escritura, que son fundantes dentro de lo escolar, ya que la escuela nace con la escritura y la lectura incorporadas de antemano (Álvarez, 1995). Además, teniendo en cuenta la escritura como una tecnología (Ong, 1987), el lazo de la escuela con esta no es nada nuevo: "El vínculo entre escuelas y tecnologías es fundacional. La escuela en sí misma nace de la mano de la imprenta para responder a las necesidades de la nueva tecnología: enseñar a leer para crear un público lector” (Abramowski y Tarasow, 2015, p. 146). La oralidad, aunque ha estado reivindicándose en los últimos tiempos en la escuela (Gutiérrez, 2014), se sigue enfocando en los procesos de habla y de la voz (con la presuposición de la escucha), y, en muchas ocasiones, como una herramienta que usa el maestro para el acercamiento de los niños a la lectura y la literatura (Chambers, 2007), ya que lo que puede hacer un maestro con su voz en el aula puede servir como provocación de escritura.
} 
interpersonales, que, atravesadas por formas combinadas de hablar, representar y escribir, impactan nuestras maneras de recibir, leer y escuchar, extendiéndose ampliamente en terrenos como el educativo ${ }^{8}$. Así, emerge una especie de oralidad terciaria (Ángel-Botero y Alvarado-Duque, 2016) u oralidad del tercer entorno (Vázquez, 2014) atravesada por todo tipo de tecnologías y dispositivos que parecieran imprescindibles en los actos comunicativos y que constantemente plantean una lucha contra la dispersión y la falta atención, características que se ahondan en estas nuevas subjetividades signadas por lo tecnológico (Sibilia, 2005, 2015).

La oralidad mezclada con la imagen tecnologizada y con todo tipo de elementos audiovisuales y escritos hace que lo que se comunique tienda a estar en un sentido más productivo que receptivo, lo que produce un alejamiento de la detención y la paciencia que requiere la escucha. Es común, por ejemplo, que en las redes se perciba que se está hablando siempre, pero, también, que no se espera la escucha y, muchas veces, se replica sin escuchar en toda su dimensión. Entonces, se generan interacciones ofensivas y agresivas, casi como si no se aceptara la diferencia.

Los cambios que han producido las nuevas formas de comunicarnos a través de los medios tecnológicos han transformado drásticamente nuestras subjetividades, nuestros comportamientos, nuestros discursos, nuestra escucha, nuestra conciencia y nuestra manera de percibir y asumir el conocimiento (Ong, 1987; McLuhan, 2016). Sin pretender demonizar estas nuevas formas de comunicarnos, es necesario reconocer que hoy nos cuesta mucho estar presentes y atentos en algún lugar. Las tecnologías digitales han provocado una subjetividad ansiosa muy útil a otros aspectos del mundo contemporáneo, como la lógica del mercado, que nos quiere afanosos, dispersos y no satisfechos con nada,

\footnotetext{
${ }^{8} \mathrm{Nada}$ mejor para percibir esta incidencia que lo que está afrontando el terreno de lo educativo con respecto a la pandemia en boga (Tonucci, 2020; DIE-UPN, 2020; Skliar, 2020).
}

porque siempre queremos más de otra cosa, como lo plantean Narodowski (1999) y desde Sibilia $(2005,2015)$.

Atendemos a unas formas de hablar y de escuchar totalmente diversas y distantes a milenios de aquellas que solo se regían por la palabra hablada, que, según McLuhan (2016), fue la primera gran tecnología y cuyo auge característico se dio en una remotísima oralidad primaria. También estamos a una gran distancia de aquella forma que, hace tan solo unas pocas décadas, regía esa oralidad secundaria atravesada por la escritura, que ha sido por siglos otra de las tecnologías más relevantes.

En ningún otro tiempo en la historia de la humanidad hubo tantas opciones para comunicarnos, hablar, conversar, discutir y acercarnos en demasía como en este nuevo siglo. Según Chambers (2007, p. 11): "La gente nunca había hablado tanto. El teléfono, la radio, el cine, la televisión y las grabaciones en audio y video han incrementado nuestras oportunidades de conversar". Sin embargo, se percibe un distanciamiento de las voces y los cuerpos, que se representa muchas veces en la dificultad para hablar y escuchar cara a cara.

Asimismo, nunca antes en la historia se había escrito tanto como en la era digital que a su vez, crea un ilimitado orden textual que, entre dos aguas, se niega a desechar nada y está inundado de información que nunca se alcanzará a asimilar en su totalidad, porque hace emerger

una forma paroxística a la tensión, presente desde la Biblioteca de Alejandría, entre el miedo de la pérdida, la desaparición, el olvido $y$, por otro lado, el temor al exceso, a los libros inútiles, al desorden de los discursos [...] (Chartier citado en Mendoza, 2019, p.4).

En este panorama emergen esas nuevas representaciones de la oralidad que irrumpen con chats, emoticones y otro tipo de imágenes que 
rememoran la etapa medieval, en la que la oralidad y la escritura tenían un punto de encuentro “pre-textual”, según Mendoza (2019a, p. 7):

[...] salvando las distancias, las emulsiones ciberculturales implicadas en nuestro cambio de milenio podrían ser equiparables a las superposiciones entre iletrismo, cuasi-letrismo y letrismo propias del pasaje del siglo IX al siglo $X[. .$.$] podríamos estar en presencia$ de un nuevo horizonte oral de la escritura. ¿Podríamos pensar acaso que en este tipo de práctica cruzada entre la oralidad y la escritura la fijación previa del texto se empecina en pervivir alli donde la variance de la fiesta contemporánea le quiere quitar su antigua fijeza? (p.7).

Teniendo en cuenta que las nuevas formas de escritura están combinadas con todo lo que circula en internet (videos, audios, performances, etc.), y que ya no se pueden "concebir como islas separadas los textos, las imágenes y su digitalización” (García-Canclini, 2015, p. 4), hoy hay unas "formas insumisas de lectura" (p. 30), que se cruzan en Internet y que permiten la edición, mezclándose con otros lenguajes.

Así, paradójicamente, el cuerpo y la voz vuelven a cobrar dimensiones perdidas en detrimento de la escritura, que hasta ahora tenía un lugar preponderante. Se recomponen y mezclan a través de imágenes, videos u otras formas que, si bien no pueden remplazar la corporalidad y la presencia en sí, les dan relevancia a través de otros medios. Aunque, asimismo, nunca antes se había escrito tanto al lado de la voz: chats, foros, plataformas de simulación que se extienden a un inconmensurable material de audio y video hipermedial que restablece conversaciones, conciertos y videos, reponiendo las voces. Es como si:

En nuestro actual sistema de redes se produce la fijación de la oralidad al tiempo que la propia oralidad desaparece pertrechada de nuevas formas que la definen con la lógica de la sigla, la abreviatura, el apócope, los acrónimos recursivos en los que se convierten las palabras electrónicas. (Mendoza, 2019, p. 8).

Hoy es indispensable el uso de "iconos de navegación, barras de desplazamiento, pestañas, menús, hipervínculos, funciones, dedicar tiempo a conectarse con imágenes, músicas y mapas de sitios" (García-Canclini, 2015, p.8), y en este gran hipertexto también se introducen maneras de comunicar singulares que contienen emojis, capturas de pantalla o los famosos memes. Esto implica que ya no se trata solamente de entender palabras y frases a través de un texto o de usar el alfabeto lineal, secuencial, occidental (Sahakian, 2018). Estas posibilidades permiten que el lector pueda llegar a ser autor ante el permiso que se le da de modificar el contenido de la información, adquirir o comunicar algo que no estaba determinado, casos que suceden en correos, blogs o foros, como indica García-Canclini (2015), quien añade que este entorno hipermedial es:

[...] un proceso de recomposición de la cultura a escala mundial. Hace veinte años todavia podía imaginarse la televisión como amenaza para la lectura (otros la temían como sustituto del cine o del teatro o de la vida pública urbana). Ahora, la convergencia digital está instaurando una integración multimedia que permite ver y escuchar en el teléfono móvil audio, imágenes, textos escritos y transmisión de datos. (p. 8).

A esto se suma el estilo de vida contemporáneo que plantea, en gran medida, la mera sobrevivencia para empujar a las jóvenes generaciones a leer puntualmente de acuerdo a lo que se le requiera en sus trabajos, para cursar determinadas materias, para postularse para la obtención de becas o para pedir financiamiento para una exposición o un trabajo específico (García-Canclini, 2015). Esto hace que proliferen las lecturas 
tipo "zapping”, efímeras y fragmentadas, alimentadas por dispositivos como el computador y el celular, ajenas a las que la formación escolar defiende (lineales, progresivas y completas), porque es imposible seguir en ese horizonte si tienes "17 ventanas en la computadora, 3 libros abiertos, una llamada telefónica, la música sonando y el gato entrando... y te acostumbras: ya no es ruido sino lo cotidiano" (García-Canclini, 2015, p. 19).

Pero lo anterior, no es un asunto que cale en el solo juzgar si es falta de cultura o mera superficialidad irrelevante. Sabemos que es algo más complejo, ya que, por un lado, se ha planteado de manera apocalíptica el fin de los libros y se cuestiona a los jóvenes por ser no- lectores y transgresores de la escritura. Por otro lado, también se evidencia que nunca antes como ahora, en esta era digital, hubo tanta producción y consumo de textos en los jóvenes (Sahakian, 2018).

Según Anne-Marie Chartier (2004) las formas de lectura para el estudio cambiaron de tal manera que es "posible encontrar no-lectores de libros entre los futuros dirigentes económicos, pero también entre futuros investigadores y universitarios científicos" (p. 188). Esto dado que es usual leer para cumplir con un trabajo de forma rápida, discontinua e informativa. Esta autora ha señalado que las lecturas fragmentarias y dispersas son comunes en egresados universitarios y en diversas poblaciones de la cultura letrada. En las carreras de letras y humanidades, incluso, los estudiantes han declarado "únicamente cumplir con las lecturas obligatorias” (p. 189). Es decir, se ha expresado abiertamente que no se leen libros completos en ámbitos específicos en los que la lectura es innegociable, lo que pareciera analógico al zapping televisivo o al devenir de las imágenes constantes y cambiantes de los medios audiovisuales y de la conectividad instantánea de Internet. Los fragmentos remplazaron los libros enteros, y aquellos se entremezclaron con otras formas de expresión que circulan por la red y producen múltiples y nuevos sentidos (Sahakian, 2018).
Así, leer y escuchar hoy implica saber discriminar y clasificar los vastos multicontenidos que ofrece la amplitud de la información actual:

Filtrar, discriminar y elegir [...] se han vuelto indispensables tanto para los escritores $y$ artistas adultos como para los emergentes. Lo aprendemos también los profesores, urgidos por la necesidad de combinar recursos publicados en papel e Internet si queremos no quedar rezagados ante la variedad de contenidos, soportes y perspectivas con que se actualizan nuestros alumnos. Lo aprenden laboriosamente algunos periodistas $y$ politicos que procuran estar a la altura de los receptores de sus mensajes. (García-Canclini, 2015, p. 20)

Esto ha llevado, también, a que estén emergiendo novedosas prácticas de escritura entre escritores, periodistas o lectores activos e innovadores que acuden a lo discontinuo, al copiar y pegar. Asunto que no es tan reciente, ya que este uso de trozos y residuos empleados con fines distintos de los de sus textos de procedencia fueron experimentaciones y búsquedas de algunas minorías en la literatura y el arte modernos como Mallarmé, Joyce, Cortázar, Duchamp, entre otros (García Canclini, 2015). Esto, sin embargo, tiene también un límite, ya que, aunque está aliado a la creatividad, la innovación o la recursividad inventiva, también ha abierto puertas desde las que se discuten el plagio y la no originalidad. Así, surge la pregunta inevitable: ¿Desde dónde y hasta dónde va lo no original en el tercer entorno?

El escritor Fernández Mallo (citado en Mendo$\mathrm{za}, 2014$ ) dice que la obra como un original es un mito romántico, ya que no hay un autor único, porque este se diluye en miles de informaciones tanto como la evolución biológica y la cultural que también se basan en la copia. El recién nacido copia a la madre como parte de su supervivencia, y no menos el arte ha sido una copia continua en la que los artistas han copiado a sus predecesores, lo que en sí mismo hace que haya 
continuidad de la existencia de la pintura o de la novela, entre muchas formas del arte. La evolución es una sucesión de copias.

En ese sentido se podría plantear que no hay nada nuevo bajo el sol, famosa frase del Eclesiastés bíblico, que en otros terrenos nos lleva a Kenneth Goldsmith (2015), cuando relaciona el patchwriting como una práctica que recoge fragmentos, palabras, frases de otros y como "un truco que los estudiantes usan todo el tiempo, reescribiendo, por ejemplo, un artículo de Wikipedia en sus propias palabras" (p. 23). Esto es considerado por la academia tan grave como el plagio, pues está obsesionada con censurar este tipo de prácticas, estableciendo sanciones para el caso. El autor en mención en sus cursos de escritura no-creativa, quiere romper con la ortodoxia de la academia, ya que en esta pareciera que la escritura está ajena a Internet, como si este no se hubiera inventado. Incluso, el mismo "mundo literario todavía se escandaliza por los mismos episodios de fraudulencia, plagio y engaño que causarían risa en los mundos del arte, la música, la computación o la ciencia” (p.28).

Así, si no hay nada nuevo bajo el sol, si no hay temas nuevos en ningún campo de creación y si no hay nada que fundar, porque ya todo está dicho, creado o constituido, entonces, solo queda hacer emerger la marca de singularidad y la huella digital, desde las posibilidades únicas que hacen emerger la propia expresión que interpreta y re-crea lo ya dado de antemano. Esto, guardando las distancias, lleva a pensar que la "originalidad no existe, sólo lo auténtico”, tal como lo cita Goldsmith (2015, p. 31).

Pero no se busca hacer una apología de la copia, ni mucho menos. Si bien se ha planteado que "con internet la intensidad del plagio ha llegado a niveles extremos" (Goldsmith, 2015, p. 24). También ahí, precisamente, está el problema, la búsqueda y la solución, porque no se trata de que "si no quieres que lo copien, no lo subas a la red" (p. 35), sino de considerar que

Lo que estamos experimentando por primera vez en la historia es la habilidad del lenguaje de alterar todos los medios, ya sean imágenes, video, música, o texto; se trata de algo que representa una ruptura con la tradición $y$ traza el camino para nuevos usos del lenguaje (p.52).

En este panorama surgen muchos textos y escenas que sirven de antecesores a lo que puede estar sucediendo en esta época digital frente al patchwriting, lo que para algunos está cercano al plagio, copia, no-originalidad, mientras que para otros es y sigue siendo una forma de creación, como de alguna u otra manera ya lo trató Borges (1996) singular y creativamente en su "Pierre Menard, autor del Quijote" cuando el personaje del relato reconstruye (no los copia) dos capítulos del Quijote porque estaría en una época distinta a la de Cervantes. Este horizonte nos lleva a los libros apócrifos de la Biblia, El Quijote apócrifo de Avellaneda o a las versiones cinematográficas o televisivas basadas en obras literarias en las que siempre hay comparación con las fuentes “originales", etc.

En esta reflexión sobre la creación desde lo ya creado, no se pasa desapercibido lo planteado por Goldsmith (2015) y por Fernández-Mallo (citado en Mendoza, 2014), para quienes para permanecer y sobrevivir pareciera que es necesario estar copiándonos e imitándonos. Pero se trata de un sentido de reproducción en el que cada copia tiene su huella de singularidad y originalidad dada por la expresión particular del creador.

\section{Al final del camino: ¿Qué nos queda como lectores y como escuchas?}

Quienes estamos en el medio académico hemos pasado, en dos décadas, de los libros de texto a las fotocopias, siguiendo al PDF y de ahí a la lectura directa en línea (García-Canclini, 2015). Esta transformación de la lectura implica una especie de Biblioteca de Alejandría infinita, en 
la cual se pueden encontrar textos sobre cualquier tema, lo que, a su vez, lleva a que el lector contemporáneo sea como un DJ del pasado, que samplea tradiciones y la PC sea su consola según Mendoza (citado en Sahakian, 2018). Por ello lo que escoja el lector, usuario o consumidor digital marca su presente: citas, fragmentos, videos, imágenes, canciones, poemas, obras de arte sirven para rediseñar y recomponer nuevas melodías actuales, de múltiples voces y por supuesto, editables (sin que se llegue al plagio). Así, la constelación de obras que se reescriben, se rearman, no tienen fin ni son cerradas. (Sahakian, 2018).

Del lado de la escucha, se plantea siempre una forma de comunicar atravesada por el deseo y mediada por la voluntad en cualquiera de los tres momentos o entornos señalados. Hemos escrito-hablado mucho y seguimos escribiendo-hablando mucho y nos seguimos enredando en un sinfín de discursos, que son ríos de saliva y tinta (ahora huellas digitales), que muchas veces no nos transforman. Restaría, entonces, el silencio como un camino, como un remanso, como un retiro (Nerburn, 1994; Le Breton, 2006), en el sentido que nos lleve a leer y no replicar ni hablar de inmediato, como hacían aquellos que leían ciertos tipos de textos para impregnarse de ellos y meditarlos a profundidad (Le Breton, 2006; Foucault, 2002). Asunto que no está muy lejos de lo que irrumpe desde las Borraduras digitales referidas por Cussen (2018), quien describe ejercicios estéticos en los que se borran palabras o textos (incluso de grandes obras como En busca del tiempo perdido de Marcel Proust) o se suprimen sonidos de grabaciones y se hace emerger aquello que realmente nos une como lectores o como escuchas: espacios en blanco, pausas, silencios, resonancias que no se pueden transcribir. Además, emergen sonidos del aire en la boca, movimientos de la saliva y "otros gestos sonoros no reconocibles completamente como fonemas, es decir, incapaces de ser considerados dentro del lenguaje ni menos de ser transcritos" (p. 68).
Es decir, lo que para un caso específico de borradura sonora tiene una intención muy clara como lo refiere Lane (citado en Cussen, 2018, p. 68):

Escuche a sus amigos, escuche a sus enemigos $y$ escúchese a sí mismo. Le garantizo que no hay nada en estas grabaciones con lo que no esté de acuerdo; en cambio, encontrará la prueba cruda y vital de sus más humanas similitudes. Mientras escucha estas grabaciones, la adicción al lenguaje perderá su control sobre usted. La repetición diligente de esta práctica es el primer paso en el camino hacia la paz.

Se podría decir que, después de esto, aunque la búsqueda continua, ¿para qué más palabras? Sin embargo, lo que resta enfatizar es que esta relación entre oralidad y escritura es una cuestión compleja y densa, que, de antemano, está atravesada por perspectivas históricas, socio-antropológicas y educativas, entre muchas otras. Vale la pena preguntarnos, entonces, si este complejo oralidad y escritura en el tercer entorno está en comunión con la estética del fragmento y el zapping, o si no sería productor de un nuevo tipo de "clase escucha - lectora" que paradójicamente no concibe la oralidad y la escritura como está concebida en la escuela o en los entornos académicos.

Esta emulsión que se produce entre oralidad (habla-escucha) y escritura-lectura en la era digital deja abiertas las puertas para seguir reflexionando y construyendo teórica e investigativamente. Si en algún tiempo estas prácticas, históricamente, estuvieron separadas, en esta era aparecen licuadas, emulsionadas en un torbellino en el que la voz, el discurso, la escritura, la imagen y cualquier forma transmedial pueden ser producidos, escuchados y recibidos de manera simultánea y aglutinante en el universo audiovisual y virtual. Lo que ocasiona un desajuste en las formas de atención y de recepción, en la lectura y en la escucha. 
Trascender esto requiere de la paciencia y de la espera que ofrece el silencio, aunque la ideología moderna de la comunicación parece no aceptarlo (Le Breton, 2006). Este es condición ineludible para escucharse a sí mismo, al otro y lo otro. Sin embargo, le tenemos fobia porque nos causa incomodidad, miedo y confusión, por lo que nos llenamos presurosa e impacientemente con todo tipo de ruidos, imágenes y sonidos que nos distraen de nosotros mismos y en los que la captura se acentúa en la cosa, el objeto y el dispositivo tecnológico, en detrimento de los sujetos (Rojas, 2020).

Hoy más que nunca, en esta época de pandemia, tenemos todo a mano, pero, a la vez, todo se nos presenta distante, lejano y efímero. La virtualidad nos ha empujado de manera imparable en esas formas emulsionadas de la voz, la escritura, la imagen, el sonido, el ruido y el cansancio como su señal más inminente. Quizás, sin embargo, la salida más sencilla está en la detención, la pausa del silencio, cuyo clamor imperceptible nos ancla en el escuchar, escucharnos y ser escuchados en lo fugaz y lo trascendental de nuestra existencia.

\section{Referencias}

Abascal-Vicente, M. D. (2002). La teoría de la oralidad. [Tesis doctoral, Universidad de Alicante]. Repositorio Institucional de la Universidad de Alicante. http://rua.ua.es/dspace/ handle/10045/4151

Abramowski, A., y Tarasow, F. (2015). Imágenes de la escuela, las promesas de la tecnología. En D. Niedzwiecki (Comp.), Sola, fané y descangayada. Conversaciones sobre la escuela (pp. 126-156). Facultad Latinoamericana de Ciencias Sociales (FLACSO). http:// biblioteca.clacso.edu.ar/Argentina/flacso-ar/20171108052810/pdf_726.pdf
Ángel-Botero, A. y Alvarado-Duque, C. A. (2016). Oralidad terciaria: mirada ecológica a la radio digital. Palabra Clave, 19(2), 473-500. http://www.scielo.org. co/scielo.php? script $=$ sci_abstract\&pi$\mathrm{d}=$ S0122-82852016000200006\&lng =e\&nr$\underline{\mathrm{m}=\mathrm{iso} \& \mathrm{t} \operatorname{lng}=\mathrm{es}}$

Borges, J. L. (1999). Del culto de los libros. Otras inquisiciones. Alianza Editorial.

Borges, J. L. (1996). Obras Completas. Emecé Editores.

Cassany, D., Luna, M. y Sanz, G. (1994). Comprensión oral. Enseñar lengua. Graó.

Chambers, A. (2007). Dime. Los niños, la lectura y la conversación. Fondo de Cultura Económica.

Chartier, A. M. (2004). Enseñar a leer y a escribir. Una aproximación histórica. Fondo de Cultura Económica.

Contreras, I. (2015). Ruptura y continuidad comunicativa. De la sonoridad de la palabra al audiovisual. En G. Paulin e I. Contreras (Coords.), Oralidades y cultura. Conferencia llevada a cabo en el III Congreso Iberoamericano de estudios sobre oralidad, Ciudad de México, México.

Corominas, J. (1987). Breve diccionario etimológico de la Lengua Castellana. Gredos.

Cussen, F. (2018). Borraduras digitales. Virtualis, 9(17), 55-82. https://www.revistavirtualis.mx/index.php/virtualis/article/ view/274/272

Dolar, M. (2007). Una voz y nada más. Manantial.

Ferreiro, E. (2001). Pasado y presente de los verbos leer y escribir. Fondo de Cultura Económica. 
Foucault, M. (2002). La hermenéutica del sujeto. Fondo de Cultura Económica.

Gadamer, H. (1998). Verdad y método II. Ediciones Sígueme.

García Canclini, N. (2015). Leer en papel y en pantallas: el giro antropológico. Hacia una antropología de los lectores. Ediciones culturales Paidós.

Goldsmith, K. (2015). Escritura no-creativa. Gestionando el lenguaje en la era digital. Caja negra.

Gómez de Silva, G. (1991). Breve diccionario etimológico de la lengua española. Fondo de Cultura Económica.

Gutiérrez-Ríos, M. Y. (2014). Concepciones y prácticas sobre la oralidad en la educación media colombiana [Tesis doctoral, Universidad Distrital Francisco José de Caldas]. Sección de publicaciones Universidad Distrital Francisco José de Caldas. https://editorial.udistrital. edu.co/detalle.php?id $=78 \& \mathrm{f}=6$

Gutiérrez-Ríos, M. Y. y Uribe-Hincapié, R. A. (2015). Cuando es posible hablar y escuchar mejor de cómo ya hablamos y escuchamos. Oralidad-es, 1(2), 192-204. https://revistaoralidad-es.com/index.php/ro-es/article/ $\underline{\text { view } / 28}$

Larrosa, J. (2016). Experiencia y alteridad en educación. En C. Skliar y J. Larrosa (Comps.), Experiencia y alteridad en educación (pp. 1344). Homo Sapiens Ediciones.

Le Breton, D. (2006). El silencio. Sequitur.

Lenkersdorf, C. (2008). Aprender a escuchar. Enseñanzas mayas-tojolabales. Plaza y Valdés.

McLuhan, M. (1996). Comprender los medios de comunicación. Las extensiones del ser humano. Paidós.
Mendoza, J. (2014, agosto 16). Fernández Mallo. Ensambles de un escritor AfterPop. (Entrevista con Agustín Fernández Mallo). Revista N. https://tlatlandblog.tumblr.com/ post/95122990158/fernández-mallo

Mendoza, J. (2019). Un nuevo orden textual. Diálogos con Roger Chartier. Documentos de trabajo del seminario Maneras de leer en la era digital. Universidad de Buenos Aires.

Mendoza, J. (2019a). El imperio textuario. Documentos de trabajo del Seminario Maneras de leer en la era digita., Universidad de Buenos Aires.

Nancy, J. L. (2015). A la escucha. Amorrortu.

Narodowski, M. (1999). Después de clase. Noveduc.

Navarro, J. (2001). Lectura y literatura. En F. Jurado y G. Bustamante (Comps.), Los procesos de la lectura (pp. 79-91). Magisterio.

Nerburn, K. (1994). Neither Wolf nor Dog. On Forgotten Roads with an Indian Elder. New World Library.

Niño, H. (2014). La voz y la letra: marcas en litigio. En M. E. Rodríguez y R. Pinilla (Eds.), Oralidades. Saberes y experiencias de investigación en red (pp. 57-76). Bogotá, Colombia: Universidad Distrital Francisco José de Caldas.

Ong, W. (1987). Oralidad y Escritura. Fondo de Cultura Económica.

Ong, W. (2017). The Presence of the Word. Yale University Press.

Platón. (2007). Carta VII. Diálogos. Gredos.

Platón. (1995). Fedro. Diálogos. Planeta. 
Rojas Alvarez, G. (2019). Escucha y conversación: un acercamiento desde las voces de maestros. [Tesis de doctorado, Universidad Nacional de La Plata]. http://www.memoria.fahce.unlp.edu. ar/library? $\mathrm{a}=-\mathrm{d} \& \mathrm{c}=$ tesis \&d=Jte1753

Rojas Alvarez, G. (2020). El silencio... una aproximación. Calle 14 Revista de Investigación En El Campo Del Arte, 15(28). https://revistas.udistrital.edu.co/index.php/c14/article/ view/16264/16044

Sahakian, S. (2018). Juan José Mendoza investiga las Maneras de Leer en la era digital. El lector contemporáneo es como un DJ. ar/159087-el-lector-contemporaneo-es-como-un-dj?fbclid=IwAR3vumOA6hXpHqETf6mD-a6inHqiEyHsNR2UVh30V1UfCFNPnuLJocoJCFE

de Saussure, F. (1998). Representación de la lengua por la escritura. Curso de lingüística general. Fontamara.

Sibilia, P. (2005). EI hombre postorgánico: Cuerpo, subjetividad y tecnologías digitales. Fondo de Cultura Económica.

Sibilia, P. (2015). Jamás me enseñaron a educar! En E. Antelo (2015), Pedagogías silvestres (pp. 236-258). Arandú.

Skliar, C. (2020). Conversaciones entre cualesquiera. Entre la prisa y la detención: sosteniéndonos en la incertidumbre. https://conversacionesentrecualesquiera.tumblr.com/tagged/Las\%20 Conversaciones

Szendy, P. (2015). En lo profundo de un oído. Una estética de la escucha. Ediciones metales pesados.

Sontag, S. (1997). La estética del silencio. Estilos Radicales. Santillana.

Tolchinski, L. (2001). Aprendizaje del lenguaje escrito. Anthropos.

Viceministerio Educación Preescolar, Básica y Media. (2020, mayo 29). Charlas con maestros No 4 [Video]. YouTube. https://www.youtube.com/watch? $=\mathrm{kd} 2 \mathrm{Esj} \_\mathrm{t} 8 \mathrm{Hk}$

Vázquez, M. (2014). La oralidad en el tercer entorno. Oralidad, comunicación audiovisual y comunicación digital. En M. E. Rodríguez y R. Pinilla (Eds.), Oralidades. Saberes y experiencias de investigación en red (pp. 123-134). Universidad Distrital Francisco José de Caldas.

Zambrano, M. (2002). Claros del bosque. Seix Barral. 